\title{
Li-Y (Lithium-Yttrium)
}

\section{H. Okamoto}

The Li-Y phase diagram was unknown in [Massalski2].

Figure 1 shows the Li-Y phase diagram constructed on the basis of a schematic phase diagram and a table of invariant reaction temperatures and compositions given in [1998Gan].

Table 1 shows Li-Y crystal structure data.

\section{Reference}

1998Gan: N.N. Ganiev, Kh.M. Nazarov, and M.D. Badalov, Interaction of Lithium with Rare-Earth Metals, Izv. Ross. Akad. Nauk, Metally, 1998, (6), p 109-112, in Russian; TR: Russ. Metall., 1998, (6), p 132-136

Table 1 Li-Y crystal structure data

\begin{tabular}{lccccc}
\hline Phase & Composition, at.\% Y & Pearson symbol & Space group & Strukturbericht designation & Prototype \\
\hline$(\beta \mathrm{Li})$ & $0-1.47$ & $c / 2$ & $\operatorname{Im} \overline{3} m$ & $A 2$ & $\mathrm{~W}$ \\
$(\beta \mathrm{Y})$ & ? to 100 & $c / 2$ & $\operatorname{Im} \overline{3} m$ & $A 2$ & $\mathrm{~W}$ \\
$(\alpha \mathrm{Y})$ & ? to 100 & $h P 2$ & $P 6_{3} / m m c$ & $A 3$ & $\mathrm{Mg}$ \\
\hline
\end{tabular}

Weight Percent Yttrium

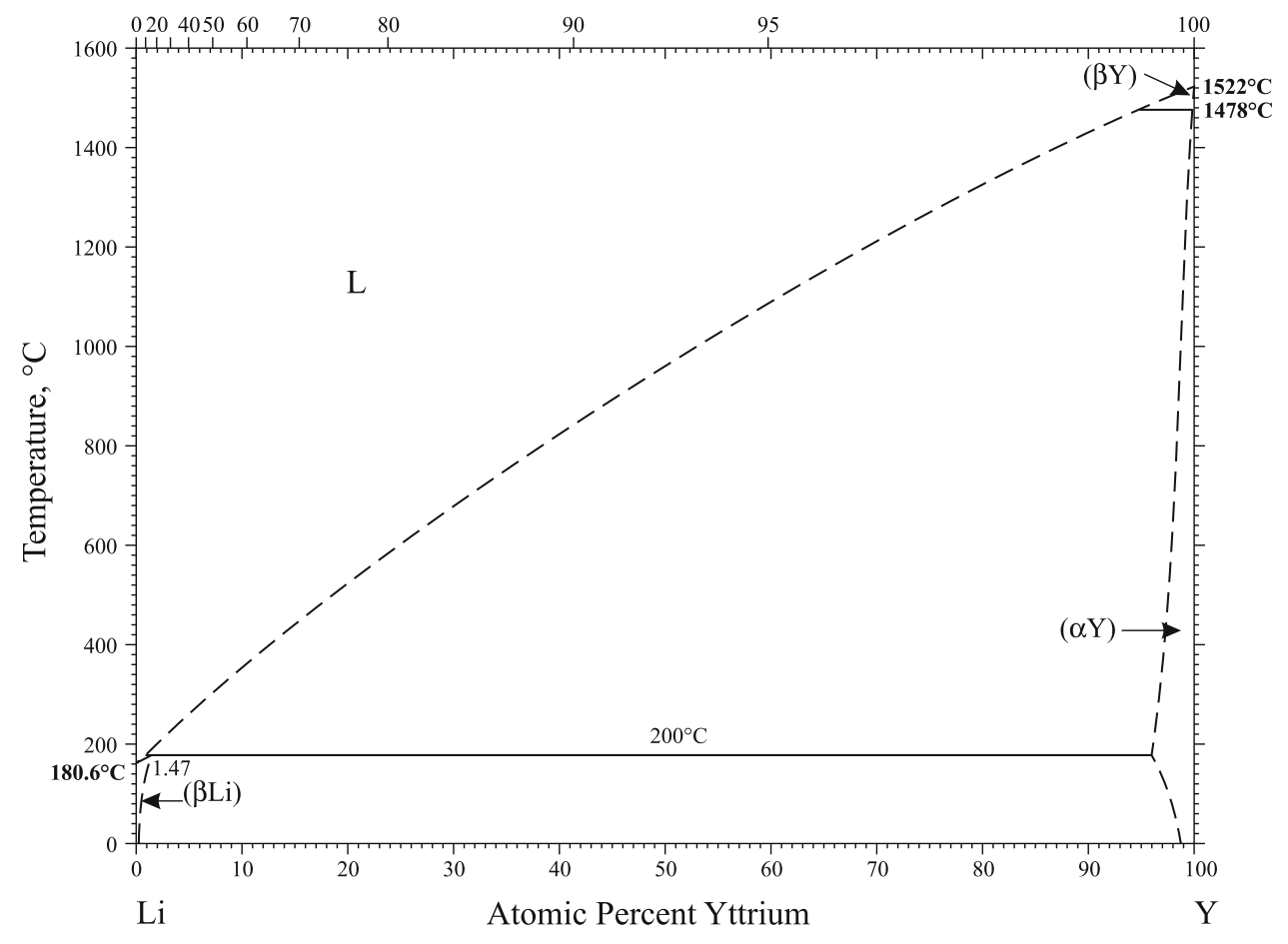

Fig. 1 Li-Y phase diagram 